\title{
LA COLONIA
}

Miguel Malagón Pinzón

\section{RESUMEN:}

Este artículo planea la hipótesis de que los actos de gobierno tuvieron control en la Colonia. Argumento que va en contravía con la tradición mayoritaria de nuestro Derecho Administrativo que establece que el control sobre la Administración Pública se inició en el siglo XX con la recepción de modelo francés. También se hace énfasis en la distinción que operó en Hispanoamericana ente competencias del gobierno y competencias de justicia, que ocasionó que las primeras fueran justificables, ante la Revolución Francesa.

\section{ABSTRACT}

This article shows how government acts were controlled during the colonial period. Contrary with the principals authors of administrative law in Colombia that thought that the control began in the CC century with the implementation of the French model. Special emphasis is made on the distinction established on Hispanic Absolutist State between the competences of justice and government, before the French Revolution.

\section{PALABRAS CLAVES:}

Actos de Gobierno, justicia, Reales Audiencias, Recurso de agravios.

\section{INTRODUCCION}

El control de la Administración Pública en Colombia es una técnica de sometimiento del poder al derecho que no surge con las revoluciones liberales, y mucho menos con la instauración en 1914 de la Jurisdicción Contencioso Administrativa, como recepción del modelo francés de control sobre la gestión administrativa. No podemos compartir la posición de quienes piensan que nuestro derecho administrativo es un ordenamiento muy nuevo que tiene menos de cien años de existencia ${ }^{1}$.

- Docente - Investigador de la Facultad de Jurisprudencia de la Universidad del Rosario

${ }^{1}$ El profesor Libardo Rodríguez es el mejor exponente de esta hipótesis véase “ Origen y Evolución de la Jurisdicción Administrativa en Colombia" en Historia y perspectivas de la Jurisdicción Administrativa en Francia y América Latina. Bogotá. Editorial Temis. 1999. p. 43-56 y Derecho Administrativo. General y Colombiano. Bogotá. Editorial Temis.1994. p.25-27 
Nosotros esbozamos otra tesis, referente a que el control de la administración en el país lleva casi quinientos años, y que su fundamento está en la Colonia ${ }^{2}$, con el denominado recurso de agravios ${ }^{3}$ a cargo de las Reales Audiencias y también con el recurso de suplicación, o mejor conocido como el "se obedece pero no se cumple" que consistía en una suspensión provisional de los actos de gobierno, por considerarlos contrarios a la realidad americana ${ }^{4}$.

\section{EL CONTROL DE LOS ACTOS DE GOBIERNO DE VIRREYES, GOBERNADORES, PRESIDENTES Y OIDORES}

La América española vivió bajo la acumulación de funciones o poderes en diversas
autoridades, fenómeno propio del absolutismo ${ }^{5}$. No obstante lo anterior, presentó la

2 "No siendo las instituciones políticas, administrativas y jurídicas (...) creaciones propias, como plantas autóctonas de nuestro suelo, sin arraigo histórico; siendo, al contrario, trasplantación de la Metrópoli a las colonias de instituciones españolas, con los cambios que naturalmente imponía la labor de adaptación, se debe explorar la colonia institucional en busca de una clave o criterio para saber y entender lo que la república heredó que no ha podido repudiar totalmente en sus ciento y tantos años de vida independiente. (...) La estructura política y social de Colombia tiene en sus líneas generales su remoto origen en las instituciones políticas y sociales de la fue durante tres siglos en América la España metropolitana. Sin referirse a las españolas, no se pueden comprender las actuales instituciones colombianas..." MENDOZA PEREZ, Diego. Prólogo al libro de ARGUELLO, Alcibíades y BUENAHORA, Luis. Derecho Administrativo Colombiano. Bogotá. Talleres de Ediciones Colombia. 1927. p. III-IX

${ }^{3}$ En la doctrina Colombiana los únicos autores que le han dado importancia y que han estudiado el Recurso de Agravios como forma de control de la administración son BECERRA LÓPEZ, Luis. Apuntamientos de Derecho Administrativo Colombiano. Santa Marta. Tipografía Bonivento Torres. S.F. p. 150-152 y SANTOFIMIO GAMBOA, Jaime Orlando. Tratado de Derecho Administrativo. Tomo I. Bogotá. Universidad Externado de Colombia. 2002. p. 288-291.

${ }^{4}$ Para este escrito sigo mis artículos "Antecedentes Hispánicos del Juicio de Amparo y de la Acción de Tutela" en Revista de Estudios Socio - Jurídicos. Volumen 5 No. 1. Abril 2003 p. 77-113 y " La Ciencia de la Policía y el Derecho Administrativo" en Revista de Estudios Socio-Jurídicos. Volumen 6 No. 1 Abril de 2004. p. 174-210. Editadas ambas por la Universidad del Rosario.

5 "Es en este período histórico intenso y variado, que se inicia con una gran expansión territorial y comercialfinanciera (favorecida por la exploración y los descubrimientos geográficos), y tras atravesar una etapa de crisis y convulsión, culmina con un relanzamiento del desarrollo económico gracias al surgimiento, aún incipiente, de la industria (preparado por el siglo de la ciencia). Las mayores dimensiones de las empresas y de los proyectos políticos y la filosofía belicista y mercantilista de los mismos acaban debilitando las estructuras señoriales - feudales (incapaces de protagonizar, sostener y dirigir tales empresas y proyectos) y propician el proceso de concentración del poder por las monarquías nacionales. Al Estado estamental de justicia le sucede el Estado absoluto de policía, que lo es tanto por lo ilimitado del poder real, como por la plenitud de la vocación de la intervención social de éste (alimentado primero por la ideología mercantilista y luego por el desarrollo del pensamiento ilustrado). Este proceso da lugar a la Ciencia de la policía y es racionalizado por ella, expresando, con entera independencia de la inicial confusión acerca de su significado, 
control de las decisiones de gobierno que causaran un perjuicio o un agravio a los particulares. Se encargó a las reales audiencias de esta dificultosa tarea. Los asuntos de gobierno los ejercían por regla general los virreyes, los presidentes y los gobernadores, y excepcionalmente otras autoridades, como por ejemplo los oidores cuando realizaban las visitas a la tierra. A todos estos asuntos que eran los de importancia se les llamaron de gobierno superior, para diferenciarlos de las cosas menudas como las tasas en los mantenimientos, las obras públicas, que venían a constituir el gobierno ordinario. ${ }^{7}$

Los asuntos de justicia, que estaban atribuidos a las audiencias, se referían a temas muy distintos, pero su núcleo duro estaba compuesto por los contenciosos, es decir por los

la idea ilustrada del progreso hacia la cultura y la civilización. La racionalidad penetra por completo el Estado, en la medida en que su fin no aparece ya predeterminado por un sistema social establecido e incuestionable, y limitado por tanto al aseguramiento de la paz y el orden conforme a dicho sistema; antes al contrario se amplía al fomento y la consecución del bienestar social ( la sociedad con <buena policía $>$ no es ya la histórica estamental, sino la articulada sobre un orden nuevo, basado en individuos iguales e ilustrados) y, en definitiva, la propia organización estatal. Por ello, no es sorprendente que el poder real asuma, en la fase final de este período histórico, un papel activo de reformas sociales y también políticas. En definitiva, la policía en que se resume la función del Estado tiene por objeto la procura del bienestar o la felicidad de los súbditos, a través de una acción positiva y conformadora que se les impone. La sistematización conforme a principios generales de la multiplicidad de reglas y medidas del poder real en tal sentido, si bien no pone en cuestión la lógica última del Estado Absoluto, produce una apreciable limitación de dicho poder. Surgen así dos fenómenos de gran trascendencia. De un lado, pasa a ser consustancial al Estado una acción pública activa, continuada y permanente - la acción llamada de policía, calificable desde la perspectiva actual de verdadera acción administrativa -, distinta de la consistente en impartir justicia y prácticamente ilimitada en sus fines. De otro lado, tiene lugar un resurgimiento del derecho como valor de orden en sí mismo y, por tanto, como regulador de la actuación pública" PAREJO ALFONSO, Luciano. Derecho Administrativo. Barcelona. Ariel. 2003. p. 7.- 8.

${ }^{6}$ Distinción que tiene origen medieval en la gubernaculum y jurisdictio. La primera era la concerniente a las armas y se " refería a las relaciones con los otros Estados y al orden interno, o de otra manera a los asuntos de Estado, llamados también arcana imperii , cuya naturaleza requería que fuesen confiados a una única persona para poder tomar decisiones rápidas y eficaces. Por su naturaleza este poder es discrecional, extra legem, no puede ser ejercido mediante leyes establecidas y se confía a la prudencia y sabiduría del rey. Si se quiere, es un poder e irresponsable porque el rey no debe dar cuenta a nadie y tiene márgenes muy amplios, ya que, en casos excepcionales, le consienten incluso establecer impuestos sin el consentimiento de los estamentos. Por otro lado las leyes, es decir, la iurisdictio : es el deber de administrar la justicia lo que convierte al rey en $<$ soberano $>$. En este campo el rey está limitado por el derecho y debe pronunciarse secundum legem . El rey es soberano en cuanto $<$ dice $>$ la justicia, ya que es $<$ la fuente de la justicia $>$. Por esto tiene un carácter sacro y es el vicario de Dios en la tierra, ya que dictar la justicia, por la concepción religiosa del medioevo, es un deber que pertenece a Dios y no al hombre. Está en el trono para pronunciar juicios justos, es decir, conformes a la ley, y es así siervo del derecho de donde deriva su autoridad, su poder es el derecho, pues lex facit regem." MATTEUCCI ,Nicola. Organización del Poder y Libertad. Historia del Constitucionalismo moderno. Madrid. Editorial Trotta. 1998. p.39

${ }^{7}$ VILLAPALOS SALAS, Gustavo. Los recursos en materia administrativa en Indias. Anuario de Historia del Derecho español. Tomo XLVI. 1976. p. 12. 
Revista electrónica de difusión científica - Universidad Sergio Arboleda Bogotá - Colombia http://www.usergioarboleda.edu.co/civilizar Reservados todos los derechos de autor Diciembre 2005

conflictos entre partes. Los asuntos de gobierno constituyeron el derecho público de la época, que se convirtió en la medula del derecho indiano, partiendo desde el propio Consejo de Indias a quien en las ordenanzas de 1571, se le fijó como principal función el buen gobierno de las Indias; la creación y categorización de los temas de gobierno se dio por la casuística, única forma posible de poder regular necesidades tan diversas de tan extensos territorios. Por su parte los asuntos de justicia quedaron, después de la ordenanza de 1571, principalmente en manos de las audiencias, estos asuntos eran mucho más rígidos, se orientaban por el derecho común-castellano y se referían principalmente a temas de derecho privado. $^{8}$

Como ejemplos de temas de justicia tenemos la organización del Consejo de Indias, de las audiencias, las autoridades provinciales y locales, las instituciones de control (visitas y residencias), los escribanos, las materias procesales y la administración de las herencias yacentes. Las materias de gobierno, en primer lugar en el plano espiritual, comprendían la organización eclesiástica, la inquisición, los hospitales, las cofradías, las escuelas, las universidades; en segunda instancia lo temporal, incluía la concesión de mercedes, la conquista, descubrimiento, y población de las indias, la emigración, el orden público, las buenas costumbres, la institución virreinal, etc. ${ }^{9}$

De igual forma existían asuntos mixtos, que eran los que realmente presentaban problemas, como la provisión de oficios dentro de la audiencia, las licencias de expediciones, las encomiendas y los repartimientos de indios, etc. ${ }^{10}$

Para ayudar a dilucidar este problema Felipe II expide la real cédula de 1568, destinada al virreinato del Perú, y a Francisco de Toledo, su virrey en particular. Allí se establece que es el virrey, quien en un caso de duda por un asunto mixto, el que deberá calificarlo como de gobierno o de justicia, y contra esta calificación no se podrá interponer el recurso de

\footnotetext{
8 TAU ANZOATEGUI, Víctor. Casuismo y Sistema. Indagación Histórica sobre el espíritu del derecho Indiano. Buenos Aires: Instituto de Investigaciones de Historia del derecho. 1992. p. 125 - 134.

${ }^{9}$ GARCIA GALLO, Alfonso. La división de las competencias administrativas en la España Moderna. Actas del II Symposio de Historia de la Administración. Madrid: Instituto de Estudios Administrativos. 1971. p. 299.
} 
Revista electrónica de difusión científica - Universidad Sergio Arboleda Bogotá - Colombia

http://www.usergioarboleda.edu.co/civilizar Reservados todos los derechos de autor Diciembre 2005

apelación ante la audiencia. Si la audiencia no estaba de acuerdo con esa valoración debía informarlo al rey. Hay que anotar que si el asunto era calificado como de gobierno, y con él se causaba agravio a alguien, se podía apelar ante la audiencia volviéndolo inmediatamente contencioso. $^{11}$

Esta real cédula

diferencia entre el orden judicial, que es el destinado a proteger los derechos de las partes, y el gubernativo cuyo fin es el bien común. Se define la supremacía del gobierno sobre la justicia en cuanto a la ejecución de mandatos dirigidos al bien común, más también la supremacía de la justicia sobre el gobierno en cuanto a la conservación de los derechos ya adquiridos, que habían sido lesionados por mandato administrativo, pero que podían ser restituidos por sentencia en el juicio de apelación. ${ }^{12}$

Lo establecido en 1568 para el Perú, se extiende a Nueva España en 1570, a Guatemala en 1587, a la Nueva Granada en 1588, a la Española en 1599, etc. ${ }^{13}$

Adicionalmente hay que comentar que la existencia de este control judicial sobre los actos de los gobernantes fue lo que llevó a la creación de las Audiencias de Panamá en 1536 y la de Chile en $1565^{14}$.

La Recopilación de 1680 reguló esta materia desarrollando tres disposiciones sobre el control judicial de los actos de gobierno. La primera era la facultad del virrey para calificar los asuntos, la segunda establecía que cuando el asunto sobrepasaba el nivel doméstico y aparecía una persona agraviada, el negocio se volvía de justicia, es decir inter partes, entre el particular afectado y la autoridad que había dictado el acto. La tercera decía que " una vez que el asunto era ya litis pendentiae, sólo a los oidores tocaba decidir y las restantes

\footnotetext{
${ }^{10}$ VILLAPALOS, Los recursos en materia. Op. Cit. p. 14 - 15.

${ }^{11}$ BRAVO LIRA, Bernardino. Protección Jurídica de los gobernados en el nuevo mundo ( 1492-1992). del Absolutismo al Constitucionalismo. en Homenaje al profesor Alfonso García Gallo. Vol. 3b. Madrid: Universidad Complutense.1992. p. 68.

${ }^{12}$ GONGORA, Mario. El Estado en el Derecho Indiano. Santiago de Chile: Instituto de Investigaciones Históricas Culturales. 1961.p. 290.

${ }^{13}$ VILLAPALOS, Op. Cit. p. 24.

${ }^{14}$ GARCIA GALLO, Alfonso. Los principios rectores de la Organización Territorial de las Indias en el siglo
} 
Revista electrónica de difusión científica - Universidad Sergio Arboleda Bogotá - Colombia http://www.usergioarboleda.edu.co/civilizar Reservados todos los derechos de autor Diciembre 2005

autoridades debían estar sometidas a su fallo que podía incluir como medida cautelar la suspensión de la ejecutividad del acto". ${ }^{15}$

Veamos ahora cuales eran los actos de gobierno recurribles. Hay que partir de la idea de que no existe una clasificación, se atacaban todas las conductas administrativas que causaran una lesión a un particular. Existía una diferencia en los órganos judiciales encargados de resolver los conflictos, así el Consejo de Indias detentaba la jurisdicción superior para todos los negocios de América, además tenía la competencia exclusiva para las quejas del gobierno general, las eclesiásticas, los conflictos de jurisdicción y todas las otras causas relativas a la real jurisdicción, al patrimonio y la hacienda. ${ }^{16}$

Las audiencias tenían competencia para conocer cualquier acto dictado por cualquier autoridad por vía administrativa siempre que hubiera vulnerado el status de un particular.

Es así como de la época de los presidentes de capa y espada en la Nueva Granada, se ha analizado un recurso de agravios del año 1623, interpuesto contra unas providencias dictadas por el oidor Juan de Villabona Zubiaurre, en una visita a la tierra de las provincias de Tunja y Pamplona. Dicha actuación consistió en trasladar el pueblo de indios de Tequia, que es de clima cálido, a Siribita que es de clima frío. El cacique, por intermedio del protector de naturales, interpone recurso de apelación ante la real audiencia. Esta decidió el caso concediendo la razón al Cacique. ${ }^{17}$ Dicha providencia es recurrida por el fiscal y confirmada por la audiencia el 12 de septiembre de 1624 .

XVI. en Estudios de Historia del Derecho Indiano. Madrid. Instituto de Estudios Jurídicos. 1972. p. 689.

${ }^{15}$ VILLAPALOS, Op. Cit. p. 37

${ }^{16}$ Ibid. p. 42.

${ }^{17}$ AUTO

En la ciudad de Santa fe a 30 días de agosto de 1624 años, los señores presidente y oidores de la Audiencia Real de su majestad de este Nuevo Reyno de Granada, don Juan de Borja, caballero de la orden de Santiago, presidente. doctor Lesmes de Espinosa Saravia, licenciado don Antonio de Obando, doctor don Francisco de Sosa y licenciado don Francisco de Saavedra, oidores. Habiendo visto los autos del protector de los naturales de este reino por don Simón cacique del pueblo de Tequia, encomienda del capitán Antonio de Enciso, con el licenciado Juan Ortiz de Cervantes, fiscal de su majestad. En esta Real Audiencia sobre que habiendo el señor doctor Juan de Villabona Zubiaurre, oidor que fue de esta dicha Real Audiencia y visitador de las 
Este caso representa una función de gobierno realizada por la real audiencia, digamos que esta sólo secundariamente ${ }^{18}$ desarrollaba materias de gobierno y la típica de estas era la visita a la tierra, que "tenía por finalidad verificar la ejecución de las leyes, procurar a los indios justicia y, en general intervenir donde pareciera ser necesario."19

En la Audiencia de Chile ocurrieron otros casos de recursos de agravios, veamos:

1. La Real Audiencia de Santiago, conociendo de una apelación interpuesta por don Pedro Díaz Valdés contra un decreto del Gobernador, don Francisco García Carrasco, que le había privado de su oficio de Asesor General de la Presidencia, en el mes de marzo de 1810 desarrollaba con gran rigor jurídico los

provincias de Pamplona y Tunja mandado a los autos dichos indios agregar y juntar en la población que hizo en el sitio que llaman de Siribita por su auto que para ello proveyó en 27 de marzo del año pasado de 1623 y pretenden los dichos indios sin embargo de lo mandado y ejecutado en la dicha razón por el dicho señor visitador, se han de volver a su sitio y población antigua que tenían los dichos indios de Tequia, que se contradice por el dicho fiscal de su majestad y se pretende deberse guardar cumplir y ejecutar lo ordenado y mandado por el dicho señor visitador y habiendo visto el ofrecimiento hecho por el capitán Antonio de Enciso encomendero de los dichos indios por carta escrita al real acuerdo su fecha en 4 de octubre del año pasado de 1623, reconocida por el susodicho en presencia de los dichos señores en 27 de este presente mes y año, por la cual ofrece dar a los dichos indios ocho meses de doctrina mudándolos al dicho su sitio antiguo de Tequia y vistas las probanzas y demás autos hechos en la dicha razón. Y dijeron que sin embargo de lo proveído, hecho y ejecutado por el dicho señor oidor visitador debían de mandar y mandaron que el dicho cacique y demás indios del pueblo de Tequia se desagreguen de la dicha población de Siribita y se vuelvan y junten en el sitio de Tequia que antes tenían. Y para ello se les vuelvan a sus tierras resguardos y las labranzas que poseían cuando se agregaron a la dicha población de Siribita, las cuales se les mandan restituir para el dicho efecto a los dichos indios por cualesquiera personas que las tengan ocupadas y los dichos indios se pueblen en el dicho sitio de Tequia en forma política. Los señores mandaron se haga una iglesia suficiente para ser doctrinados en las cosas de nuestra santa fe católica y para la dicha doctrina se ha de nombrar un sacerdote religioso de la orden de santo domingo, el cual ha de hacer doctrina a los dichos indios todo el año dándole y pagándole el estipendio de ocho meses y para que se provea conforme al patronazgo real se de noticia a los prelados y a los demás indios que quedan juntos y agregados en la dicha población de Siribita, mandaron se les den nueve meses de doctrina los cuales paguen sus encomenderos, respecto según los indios a que cada uno tuviere como obligación el dicho sacerdote de asistir por el dicho estipendio todo el año. Y así lo proveyeron y mandaron.

Pronuncióse este auto por los señores presidente y oidores de la Audiencia Real de su majestad estándola haciendo pública en Santa fe a 30 de agosto de 1624 años. A.G.N.(Bogotá).Visitas Santander. Tomo IX. 1623. folios 759r. y v.

18 "Sólo secundariamente por las funciones que se le asignaban por vía de comisión, primero en las instrucciones que se den a la misma y luego tras la reiteración de éstas ya de modo más permanente, se puede considerar como un órgano de gobierno." GARCIA GALLO, Alfonso. Las Audiencias en Indias. Sus orígenes y caracteres. en Academia Nacional de Historia. Caracas: Memoria del II Congreso Venezolano de Historia. 2 Vols. 1975. p. 384.

${ }^{19}$ MAYORGA GARCIA, Fernando. La Audiencia De Santa fe en los siglos XVI y XVII. Bogotá : Instituto 
Revista electrónica de difusión científica - Universidad Sergio Arboleda Bogotá - Colombia

http://www.usergioarboleda.edu.co/civilizar Reservados todos los derechos de autor Diciembre 2005

fundamentos y la necesidad de esta institución. Así a propósito de

la razón por la cual ella existía, expresaba lo siguiente:

La fuerza y la violencia la detestan las leyes de todos los gobiernos, y las de estos dominios enfrenan el poder para que no degenere en arbitrario, por los enormes perjuicios que resultan al vasallo cuando se le constituye en la necesidad de ocurrir al poder de la Majestad.

2. En 1791 conoció la Audiencia de una apelación interpuesta por el Conde de la Conquista contra un decreto del Gobernador Ambrosio O’Higgins que le mandaba contribuir con diez caballos en razón de prorrata para el transporte de los indios que habrían de concurrir a Arauco para la jura de Carlos IV, y en dicho proceso como el escribano de gobernación negara los autos, el Real Acuerdo dictaminó pasar oficio al Gobernador solicitándoselos, y en dicho escrito firmado por el regente del Tribunal, don Francisco Antonio Moreno y Escandón se expresaba lo que sigue:

A pesar de las repetidas reales disposiciones en que S.M. ordena observen con toda exactitud las Leyes de las indias que franquean los recursos de apelación a las Reales Audiencias de todas las determinaciones del Gobierno, se presentan a cada paso dudas y tropiezos que entorpecen su cumplimiento y estándole tan estrechamente encargado en los capítulos 41 y 43 de mi empleo con la recomendable circunstancia de dirigirse al bien del Estado o utilidad de la causa pública y quietud de las provincias, que por lo distante de la Península necesitan el mayor esmero y rectitud en la imparcial administración de justicia espero que no extrañe a Usía que en desempeño de esta real confianza y de lo acordado por esta Real Audiencia le haga presente que producida en ella un pedimento del señor Conde de la Conquista en grado de apelación habérsela denegado Usía de una providencia sobre prorratas de caballos y expresiones que le son indecorosas se proveyó por semanería el auto ordinario a fin de que 
Revista electrónica de difusión científica - Universidad Sergio Arboleda Bogotá - Colombia

http://www.usergioarboleda.edu.co/civilizar Reservados todos los derechos de autor Diciembre 2005

entregue los autos al escribano... y que faltara a lo

dispuesto por S.M. en beneficio de la causa pública si omitiere este examen de que pende la rectitud e imparcial administración de justicia con cuyo objeto se erigieron las Reales Audiencias.

3. En 1809 conoció la Audiencia de una apelación interpuesta por el Cabildo de Valparaíso contra un decreto del gobernador Francisco Antonio García Carrasco de 4 de enero, en virtud del cual desconocía la elección de capitulares que había efectuado la corporación, y que como perseverara en su decisión el Tribunal dio cuenta al rey y le señalaba que:

Advertirá a su sabiduría e integridad, el temerario intento del dicho Presidente en aseverar inapelables sus providencias expedidas sobre elección de capitulares tratando por este infundado principio de emborrar su escandalosa resistencia al cumplimiento de lo resuelto por este Tribunal, después de concedido por él mismo el recurso, como debió, no siéndole permitido el negarlo en ningún caso en que haya persona que se queje de agravios de cualesquiera providencia gubernativa, por ser reservada a sólo la Audiencia la calificación de si es admisible o no la apelación como se tiene declarado por V.M. en las Reales Cédulas de 19 de Marzo de 1784 circulada por la de 6 de julio de 1799 y en la de 29 de agosto de $1806 .$. No ha menester, V.M., que le funde esta Audiencia, como lo hizo al Presidente, los motivos de las citadas Reales determinaciones en favor de la causa pública y pro comunal de los vasallos, dejando a su superior penetración la del exceso que se comete con la trasgresión de las leyes más sagradas, cuales son las que como la apelación conciernen al reparo del gravamen y opresión y las que establecen y deslindan las facultades de la Audiencia y del Presidente, siendo ya un abuso intolerable y reprensible desacato a la Majestad el que cometen los Presidentes oponiéndose, como lo ha ejecutado el de este reino al puntual obedecimiento de la ley municipal y reales cédulas referidas. $^{20}$

\footnotetext{
${ }^{20}$ BARRIENTOS GRANDON, Javier. La Fiscalización de los actos de gobierno en la época indiana y su
} desaparición durante la República. Revista de Estudios Histórico-Jurídicos. Tomo XV. 1992-1993. 
Es pertinente mencionar otros ejemplos de actos de gobierno, el más clásico, según Villapalos, es el conflicto de dos titularidades que se quieren hacer valer, eran asuntos problemáticos entre españoles o entre españoles y caciques de indios, como por ejemplo en la intromisión en la resolución de causas exclusivas de los indios, o en la privación de cacicazgos. En este último supuesto se daba una excepción a la regla de la jurisdicción rogada, se admitía que la audiencia actuara de oficio.

Otros ejemplos son las lesiones causadas por abusos de los eclesiásticos; también los acuerdos y ordenanzas de los cabildos; las negligencias en la ejecución de las ordenanzas; los agravios infligidos a los indios, con énfasis en los encomendados; también estaban las sentencias absolutorias o condenatorias de demandas pecuniarias o intereses de parte dictadas en un juicio de residencia; los vicios de procedimiento; la venta de oficios. ${ }^{21}$

El principio de ejecutividad del acto de gobierno tenía carácter excepcional. Su origen se remonta a las audiencias indianas, en principio por una real cédula de 1552 sólo tres actos tenían plena ejecutividad, estos eran la realización de ordenanzas, la satisfacción de daños y la regulación de estancias de ganados; es decir que el resto de los actos de gobierno podía ser objeto de suspensión. Estas tres excepciones se sentaban sobre la idea de que las medidas de buen gobierno, de bien común, no se podían paralizar, por ello se concedía contra ellas el recurso de apelación pero en efecto devolutivo. ${ }^{22}$

Posteriormente en 1620 se expide otra real cédula en la que se le otorgaba a la audiencia el poder de decidir si aceptaba la apelación con efecto devolutivo o suspensivo, esta potestad cobijaba incluso a los actos del rey. Pero atendiendo a las excepciones consagradas en la real cédula de 1552, y en otra de 1561 que dispuso que no existía suspensión frente a las ordenanzas de gobierno que se hicieran en las ciudades. ${ }^{23}$

Valparaíso: Universidad Católica de Valparaíso. p. 113-117

${ }^{21}$ VILLA PALOS, Los recursos en materia. Op. Cit. p. 44 - 47.

${ }^{22}$ GONGORA, Op. Cit. p. 288. 
En el siglo XVIII con la reformas borbónicas llegan las Intendentes a la América hispana. Estos se constituirán en los principales funcionarios comisionados del monarca, ellos serán los encargados de fomentar la política del centralismo real ${ }^{24}$. La primera Intendencia en establecerse fue en Cuba de acuerdo a la real instrucción de 31 de Octubre de 1764. Al Intendente se le confirieron únicamente competencias de hacienda y guerra. No obstante la buena intención de la Corona, su implementación tuvo mucho rechazo, es por ello que en 1769 el Capitán General de la isla, Bucarelli, solicita su revocación argumentando que era la única Intendencia existente en América ${ }^{25}$. Posteriormente, y al llegar en 1776 al Ministerio de Indias, José de Galvez ${ }^{26}$ estableció las reformas intendenciales en la Nueva España, el Río de la Plata y el Perú. En el Virreinato de la Nueva Granada esta reforma no llega aplicarse por la revolución comunera, ${ }^{27}$ y más tarde quedó de nuevo frustrada por la independencia, pues en 1807 se ordenó la creación de las intendencias en la Nueva

\footnotetext{
${ }^{23}$ VILLAPALOS, Los recursos en materia. Op. Cit. p. 53.

${ }^{24}$ Los comisionados surgieron en el Estado Absoluto por oposición a los oficiales. Los primeros actuaban por un título revocable, mientras que los segundos adquirían su cargo por compra constituyendo una propiedad estamental que se consideraba por fuera de la disponibilidad del Príncipe. Los comisionados eran los representantes de la justicia real por oposición a la justicia estamental representada por la nobleza. Por ello la pugna entre nobleza y monarquía se presentó como un enfrentamiento entre diversas formas de justicia y no como una lucha entre justicia y administración. MANNORI, Lucca y SORDI, Bernardo. El Estado Moderno en Europa. Madrid. Editorial Trotta. 2004. p 73-74. véase también de los mismos autores Storia del Diritto Amministrativo. Roma. Editoria Laterza. 2001. p. 102-127. HINTZE, Otto. El Comisario y su significación en la historia general de la administración. en Historia de las formas Políticas. Madrid. Revista de Occidente. 1968. p. 161-174. BONNIN, Charles Jean. Principios de Administración Pública. México. Fondo de Cultura Económica. 2004. p.37-48. MANNONI, Stefano. Storia dell `Acentramento Amministrativo in Francia. Vol 1. La formazione del Sistema (1661-1815). Milano- Giufré Editore. 1994. p. 13-19. HAROUEL, Jean Louis y otros. Histoire des Institutions de l'epoque franque á la Revolution. Paris. PUF. 1987. p. 312-319.

${ }^{25}$ MORAZZANI de PEREZ ENCISO, Gisela. La Intendencia en España y América. Caracas. Universidad Central de venezuela. 1960. p. $37-38$.

${ }^{26}$ Con la muerte de Galvez en 1787 el sistema intendencial sufrió un duro revés, pero siguió subsistiendo hasta la independencia, su última Ordenanza General fue de 1803, pero no llegó a implementarse por el temor del primer ministro Manuel Godoy que entorpeciera la recién creada Ordenanza militar. SANCHEZ BELLA, Ismael. Las reformas en Indias del secretario de estado José de Gálvez ( 1776-1787). en Derecho y Administración en las Indias Hispánicas. Tomo II. Cuenca. Universidad de Castilla la Mancha. 2002. p. 1523-1524.

${ }^{27}$ PHELAN, John Leddy. El pueblo y el rey. La revolución comunera en Colombia, 1781. Bogotá: Carlos Valencia Editores, 1980. p. 19-50 y también GARRIDO, Margarita. Reclamos y Representaciones. Variaciones sobre la política en el Nuevo Reino de Granada, 1770-1815. Bogotá. Banco de la República. 1993. p. 34. KÖNIG, Hans - Joachim. En el Camino hacia la Nación. Nacionalismo en el proceso de formación del Estado y de la Nación de la Nueva Granada, 1750 - 1856. Bogotá. Banco de la República. 1994. p. 148.
} 
Revista electrónica de difusión científica - Universidad Sergio Arboleda Bogotá - Colombia http://www.usergioarboleda.edu.co/civilizar Reservados todos los derechos de autor Diciembre 2005

Granada $^{28}$, pero no tuvo efectos debido a la invasión Napoleónica a España y a los

posteriores movimientos en pro de la autonomía que se dieron en nuestro país.

El origen de estas autoridades intendenciales es Francés ${ }^{29}$, a España estos magistrados llegan en 1691 con Carlos II, quien creó una Superintendencia General de Hacienda ${ }^{30}$ y un Intendente para cada una de las 21 provincias de Castilla. Es con Felipe V, el primer borbón, con el que se instaura plenamente esta figura con el establecimiento en 1711 de la Superintendencia de Ejército y Provincia y en 1717 con la Intendencia de Ejército y Marina. ${ }^{31}$ En 1749 se promulgó otra Ordenanza en la que se ven claramente las cuatro competencias asignadas a los intendentes, la policía o gobierno, la hacienda, la justicia y la guerra. En 1766 se presenta una reforma por medio de la cual se separa el corregimiento de la intendencia, por problemas con la administración de justicia. ${ }^{32}$. El propósito de estos nuevos funcionarios era recuperar la economía del Estado que se encontraba en banca rota por la guerra de sucesión y buscar la felicidad de los súbditos ${ }^{33}$ impulsando la industria, la

${ }^{28}$ NAVARRO GARCIA, Luis. Las reformas borbónicas en América. Sevilla. Universidad de Sevilla. 1995. p. 103.

29 GARCIA TROBAT, Pilar y CORREA BALLESTER, Jorge. Centralismo y Administración: Los Intendentes Borbónicos en España. en Quaderni Fiorentini. XXVI. Florencia.1997. p.21

${ }^{30}$ En Portugal los funcionarios comisionados, llegan en el siglo XIV con los denominados Veedores de Fazenda, estos se constituyen en delegados del poder real, que producían actos de gracia, hoy mejor conocidos como actos políticos, actos de gobierno. HESPANHA, Antonio Manuel. História das Institucoes. Epocas Medieval e Moderna. Coimbra. Livraria Almedina. 1982. p.339

31 COMADRAN RUIZ, Jorge. La Real Ordenanza de Intendentes de 1782 y las declaraciones de 1783. Antecedentes franceses y españoles. en Estudios sobre la Real Ordenanza de Intendentes del Río de la Plata. Buenos Aires: Instituto de Investigaciones de Historia del Derecho. 1995. p.12

32 NAVARRO GARCIA, Luis. Intendencias en Indias. Sevilla: Escuela de Estudios Hispanoamericanos. 1959. p.10-14.

33 “ Las gentes de aquel tiempo ( el setecientos) no tuvieron temor de los dioses celosos, que se irritan cuando los mortales pronuncian palabras imprudentes. Por el contrario, clamaron que querían su parte de felicidad, que tendrían y que tenían ya. Reflexiones sobre la felicidad, Epístola sobre la Felicidad. Sobre la vida feliz. Sistema de la verdadera felicidad. Ensayo sobre la felicidad. De la felicidad (Della felicitá). El arte de ser felices (L'arte di essere felici). La felicidad ( Die Glückseligkeit). Ensayo sobre el arte de estar siempre feliz ( Versuch uber die Kunst stets fröhlich). Sobre la felicidad (Uber die Glückseligkeit), de la felicidad (Oh happiness). He aquí lo que en diversas lenguas osaron escribir como título de sus libros. Como el descubrimiento, después de haber colmado los individuos, iba a aprovechar a los pueblos; extendieron sus beneficios: Tratado de la sociedad civil y del medio de volverse feliz contribuyendo a la felicidad de las personas con quienes se vive; De las causas de la felicidad pública. De la felicidad pública; Della pubblica felicitá; La felicitá pubblica, Ragionamenti... riguardanti la pubblica felicitá; Riflessioni sulla pubblica felicitá; Of national felicity. Para tener a mano los mejores tratados sobre la cuestión, hicieron un compendio y lo titularon: El templo de la Felicidad. El bello templo estaba allí, sobre la colina feliz. La alegría se tenía a la puerta e invitaba a los humanos a comenzar, al fin, la gran fiesta de la vida". HAZARD, Paul. La pensée européenne au XVIII éme siécle. De Montesquieu á Lessing. Paris. Ancienne Libraire Furne, Bovin \& Cie. 
Revista electrónica de difusión científica - Universidad Sergio Arboleda Bogotá - Colombia http://www.usergioarboleda.edu.co/civilizar Reservados todos los derechos de autor Diciembre 2005

ganadería, la agricultura, la minería; mejorar el comercio y para ello se tenía que promover la navegación, los caminos, los puentes y los puertos ${ }^{34}$. “Y he aquí por donde la causa de policía viene a ser la piedra de toque de la institución, el nervio que ha de darle eficacia, y la vertiente realizadora, constructiva, que la diferencia y la eleva en categoría por encima de todas las similares, con aquella idea básica que la resume: el fomento"35

Este modelo llega a las Indias y se impone por primera vez en el Río de la Plata en $1782^{36}$, esta Ordenanza que le da vida a la figura del Intendente ha sido considerada como una Constitución en sentido material, porque organizó la vida social, administrativa y política de la comunidad. ${ }^{37}$ Posteriormente le siguió la Nueva España en 1787. Para el caso del Perú en 1784 comenzaron a operar allí los Intendentes basándose en la Ordenanza del Río de la Plata. La eficacia de estas autoridades, en las regiones donde operó, fue bastante

1946. p. 17-18. citado por : RESTREPO PIEDRAHITA, Carlos. Primeras Constituciones de Colombia y Venezuela. Bogotá. Universidad Externado de Colombia. 1996. p. 214-215

34 “ Es bajo los Borbones, y en especial en tiempos de Carlos III, cuando junto a los principios rectores que han inspirado la actuación gubernamental española - justicia y evangelización- se abre paso y se sitúa el del fomento de la riqueza, del bienestar y de la felicidad de lo súbditos. No importa que el logro de este bienestar material responda a los ideales filosóficos del ochocientos o a la conveniencia del Estado de aumentar la riqueza del país para poder obtener de él mayores impuestos o a las conveniencias militares de disponer de buenas comunicaciones o una firme base económica. El hecho cierto es que bajo Carlos III se concibe un vasto plan de desarrollo, aunque no quede articulado como tal. El Estado es el motor de la colonización interior de España o de las regiones americanas que permanecen estancadas, el que construye carreteras y canales, instala fábricas modelo, estimula las industrias y dignifica a los trabajadores, liberaliza el comercio y renueva la enseñanza; el que toma iniciativas, crea, organiza y controla". GARCIA GALLO, Alfonso. Sobre las Intendencias en Indias. en Los Orígenes españoles de las instituciones americanas. Estudios de Derecho Indiano. Madrid. Real Academia de Jurisprudencia y Legislación. 1987. p. 1002.

${ }^{35}$ NAVARRO GARCIA, Op. Cit.. p.10-14

36 "En 1776 se había establecido el Virreinato con capital en Buenos Aires, e incluía el área de lo que hoy es Argentina, Uruguay, Paraguay y Bolivia. El resultado fue un cambio trascendental del equilibrio geopolítico del continente, puesto que Lima, que ya había visto roto su monopolio comercial por la apertura de la nueva ruta comercial del Cabo de Hornos y que había sido la antigua capital de todo el imperio de Sudamérica, sufrió una severa pérdida de categoría. La inclusión del Alto Perú en el nuevo virreinato, con el fin de proveer a Buenos Aires con los beneficios fiscales de Potosí, preparó el camino de la división política permanente de la zona andina".Ibid. p. 96

${ }^{37}$ SAN MARTINO de DROMI, María Laura. Historia de la Administración en Argentina. en Posada Herrera y los orígenes del Derecho Administrativo Español. Madrid: INAP. 2001. p. 325. Según esta autora este documento tiene todas las características de una moderna constitución. " Contiene un preámbulo, una estructura organizacional del poder con reparto de competencias y magistraturas y un anticipo de reconocimiento de derechos y garantías, que se compatibilizan con las declaraciones a propósito de las libertades individuales que se avecinan, a fines del siglo XVIII, con la Constitución de los Estados Unidos, la Revolución Francesa y la Declaración Universal de los Derechos del Hombre. Si bien los derechos individuales no son el fuerte de esta Constitución debemos reconocer que guarda una adecuada armonía con los derechos subjetivos: intimidad, libertad e igualdad $\mathrm{y}$, con las libertades operativas de comercio e industria que se perfilan en la época, incluso con la propia Ordenanza de Libre Comercio de 1778, que sancionara el 
Revista electrónica de difusión científica - Universidad Sergio Arboleda Bogotá - Colombia http://www.usergioarboleda.edu.co/civilizar Reservados todos los derechos de autor Diciembre 2005

notoria en las capitales de provincia, porque allí controlaban el orden público reprimiendo

los desordenes y porque construyeron gran cantidad de obras públicas, tales como puentes, cárceles y el adoquinamiento de las calles ${ }^{38}$.

Los Intendentes tenían cuatro atribuciones esenciales, policía o gobierno, justicia, guerra y hacienda. Por la causa de policía o gobierno, el Intendente tenía que fomentar el desarrollo de la economía, debía cobrar los tributos, mantener en buen estado los caminos y conservar la paz pública. ${ }^{39}$ La causa de justicia introdujo la figura de los Tenientes Letrados, estos funcionarios actuaban como asesores del Intendente para asuntos contenciosos civiles y criminales en la capital de las provincias, asumiendo para ello las competencias que antiguamente le estaban asignadas a los gobernadores y virreyes .Las audiencias conocían

las apelaciones que se interpusieran contra los autos y sentencias que como jueces ordinarios proferían estos magistrados. Esta situación garantizó más firmemente la independencia de los Letrados frente a los Intendentes ${ }^{40}$. Por regla general los Intendentes no eran abogados "por eso el mismo rey se encargó de exaltar la posición de los Tenientes letrados como jueces ordinarios, al ordenar que los intendentes nunca debían separarlos del conocimiento de sus causas..."41

De igual manera se estableció que las Audiencias conocieran en apelación de los asuntos de policía o gobierno dictados por los Intendentes que pudieran hacerse contenciosos. ${ }^{42}$

propio Carlos III...” Véase Constitución Indiana de Carlos III. Buenos Aires. Ciudad Argentina. 1999. p. 10.

${ }^{38}$ BRADING, David. La España de los Borbones y su Imperio Americano. en Historia de América Latina. Tomo II. Barcelona. Editorial Crítica. 1990. p 99

${ }^{39}$ ACEVEDO, Edberto Oscar. La causa de policía o gobierno. en Estudios sobre la Real Ordenanza, Op. Cit. p. 50 .

${ }^{40}$ MARTIRE, Eduardo. La Causa de Justicia. en Estudios sobre la Real Ordenanza de Intendentes del Río de La Plata. Op. Cit. p. 116-119

${ }^{41}$ REES JONES, Ricardo. Op. Cit. p.163.

${ }^{42}$ Según lo establecido por los artículos 5 y 14 de las Ordenanzas del Río de la Plata, concordantes con los artículos 6 y s.s. de 1 Ordenanza de la Nueva España. LYNCH, John . Administración Colonial Española 1782-1810. El Sistema de Intendencias en el Río de la Plata. Buenos Aires: Eudeba Editorial. 1962. p. 226, 241. 
Revista electrónica de difusión científica - Universidad Sergio Arboleda Bogotá - Colombia

http://www.usergioarboleda.edu.co/civilizar Reservados todos los derechos de autor Diciembre 2005

De todo lo analizado en las Indias vemos que existió una separación entre gobierno, o

policía, y justicia. A través de ella se controlaron los actos de gobierno que ocasionaran lesiones a los súbditos, este hecho los convertía en contenciosos, y ese control radicaba en las reales audiencias. Las autoridades intendenciales también eran controlables de la misma manera. Esto demuestra en primer lugar la existencia, embrionaria, de un derecho especial que se presentaba en los asuntos de gobierno o de policía y que buscaba el interés general; en segundo lugar se comprueba un control judicial sobre ese ordenamiento policial que recaía sobre el Tribunal judicial por excelencia que era la Real Audiencia, en tercer término es palpable que no existió una división de poderes propiamente dicha, pero si una separación de funciones que permitía distinguir las materias entre gubernativas y contenciosas y por último no existió un juez especializado que controlará las actuaciones de policía, sino que se tenía un juez común que resolvía todos los asuntos.

Esto nos lleva a concluir que en Colombia los actos de gobierno fueron controlados por cerca de 300 años en el período español. Estos actos de gobierno como hemos visto son herederos de la competencia medieval denominada gubernaculum, que se basaba en netos poderes discrecionales. Por eso no podemos compartir la recepción del modelo francés que, entre otras cosas, nos trajo la no justiciabilidad de los actos políticos o de gobierno por parte de la Jurisdicción Contenciosa. En Francia esta teoría de la inmunidad de los actos de gobierno tiene origen, tal como lo demuestra el profesor Duez ${ }^{43}$, en el temor del Consejo de Estado de controlar en la época de la restauración, actos producidos durante el primer imperio, y para fundamentar su decisión los calificó de políticos o de gobierno para diferenciarlos de los administrativos y así poder justificar su inhibición, teoría que subsistió hasta $1875^{44}$. Nuestro Consejo de Estado importó a mi modo de ver sin fundamento la primera parte de la teoría, es decir la de ausencia de control y así se inhibió de conocer los actos de gobierno, ignorando nuestra historia jurídica y fomentando el presidencialismo.

\footnotetext{
${ }^{43}$ DUEZ, P. Les Actes de Gouvernement. Paris. Sirey.1935

${ }^{44}$ Con el caso Príncipe Napoleón, El Consejo de Estado Francés abandona la teoría del móvil político y acoge la teoría de la lista de actos políticos que gozan de inmunidad judicial, hoy sólo existen dos: los referentes a las relaciones del poder ejecutivo con el parlamento y los de las relaciones de Francia con las potencias extranjeras y con los organismos internacionales. BRAIBANT, Guy y Otros. Les Grands Arrets de la
} 
Revista electrónica de difusión científica - Universidad Sergio Arboleda Bogotá - Colombia

http://www.usergioarboleda.edu.co/civilizar Reservados todos los derechos de autor Diciembre 2005

Jurisprudence Administrative. Paris. Dalloz. 1999. p. 19. 